The Goal The aim of this study was to examine the effectiveness of structured education about breast-feeding using a sample of high-school students. The results presented in this study are part of the results of wider research, currently on-going, into the influence of structured education on breast-feeding on changes to the intentions, knowledge and attitudes of pupils and students.

Methods The study was longitudinal, quasi-experimental, and approved by the Ministry of Science and Education of the Republic of Croatia. The experimental group consisted of 30 students from the Medical High School in Bjelovar, and the control group consisted of 30 other students from the same school. The experimental group took a structured educational course on breast-feeding, and the control group did not. The attitudes, intentions and knowledge of the subjects were measured using a validated BIAKQ questionnaire. In both groups the questionnaire was conducted twice, with a twoweek interval. The outcomes measured were the changes to the total results of the BIAKQ questionnaire and the subscales of the questionnaire. In processing the results, the following statistical procedures were used: presentation of the results by frequencies, percentages, arithmetic means and standard deviations, analysis of outliers and the normality of distribution of the results (Skewness and Kurtosis $\mathrm{z}$ values, Histogram, Q-Q diagram, Box diagram, Kolmogorov-Smirnov and Shapiro-Wilk tests), analysis of the differences between the results (t-test or the Mann-Whitney test and Wilcoxon test), and correlations are presented using Spearman's correlation coefficient.

Results Before the educational course, in relation to intentions, attitudes, knowledge and the overall results of the questionnaire, there were no significant differences between the control and experimental groups. After the experimental group had taken the educational course, the subjects achieved better results in comparison to the control group in terms of their intentions $(\mathrm{ME}=38.03, \mathrm{SD}=5.71$, $\mathrm{MK}=35.27, \quad \mathrm{SD}=5.41, \quad \mathrm{t}(58)=1.76, \quad \mathrm{p}=0.08), \quad$ attitudes $(\mathrm{MdnE}=35.52, \mathrm{MdnK}=25.48, \mathrm{U}=299.5, \mathrm{p}=0.03)$. knowledge $(\mathrm{MdnE}=35.97, \mathrm{MdnK}=25.03, \mathrm{U}=286.0, \mathrm{p}=0.01)$ and the total results of the questionnaire $(\mathrm{MdnE}=35.23$, $\mathrm{MdnK}=25.77, \mathrm{U}=308.0, \mathrm{p}=0.04)$. The results of the subjects in the experimental group after the course were also better in relation to their own results before the course, in terms of their intentions $(M=4.40, S D=5.61, t(29)=4.30$, $\mathrm{p}=0.00), \quad$ attitudes $\quad(M=13.40, \quad S D=15.37, \quad \mathrm{t}(29)=4.77$, $\mathrm{p}=0.00)$, knowledge $(\mathrm{MdnPos}=8.85, \quad \mathrm{MdnNeg}=9.5, \quad \mathrm{Z}=-$ $1.883, \mathrm{p}=0.06)$ and total results $(\mathrm{MdnPos}=15.69$, $\mathrm{MdnNeg}=9.0, \mathrm{Z}=-4.121, \mathrm{p}=0.00)$. The greatest correlation in the total results of the questionnaire after the course were shown by attitudes $(r=0.99, p=0.00)$, and the smallest by knowledge, before $(r=0.39, p=0.04)$ and after $(r=0.29$, $\mathrm{p}=0.12$ ) the educational course.

Conclusion The results confirm statistically significantly improved attitudes, intentions and knowledge regarding breastfeeding in the experimental group after taking the educational course. Earlier research by the author and research by other authors confirm that education that only brings about changes in knowledge does not necessarily also lead to changes in attitudes and intentions. Only a well-designed and structured model of education, with a multi-dimensional approach can lead to changes in attitudes and intentions, which are important predictors of behaviour. Further research is needed to define more precisely the age at which education gives the best results.

\section{A CASE REPORT OF NEUROFIBROMATOSIS TYPE 1 IN TWO BROTHERS. PRIMARY PEDIATRIC HEALTH CARE OF A CHILD WITH A CHRONIC CONDITION IN CROATIA}

Branka Pirija*. Pediatric primary care Branka Pirija MD, paediatrician

10.1136/archdischild-2021-europaediatrics.491

Introduction Neurofibromatosis Type 1 (NF1) or von Recklinghausen disease is an autosomal dominant genetic disease characterized by variability of its clinical expression of sick members of the same family. In a National Institutes of Health (NIH) consensus development conference regarding NF1, seven criteria were demarcated, of which two or more are required to establish the diagnosis of NF1. Some features of NF1 can be present at birth, but most manifestations emerge with age. Various manifestations and complications are associated with the age of the patient.

Case Description In this case, a mother and two male children have NF1. The diagnosis of NF1 in the first child was suspected based on cafe au lait macules at 6months of age. At the same time, a clinical diagnosis was made in a 28 -year-old mother. Child1, a male, 7years old, has multiple café au lait macules, axillary and inguinal freckling, subcutaneous neurofibromas, Lisch nodules, multiple T2-hyperintensities on brain magnetic resonance imaging (MRI) in the basal ganglia, cerebellum. He has macrocephaly, cognitive problems, attention deficit, sideropenic anaemia. MLPA analysis (Multiplex Ligation-dependent Probe Amplification test with SALSA MLPA kit P245-B1) showed no change in the number of copies of the genome. Child2, a male, aged 4years and 3months, with the presence of multiple café au lait spots diffuse all over the body of different sizes and axillary freckles. Brain MRI shows hyperintensities in the basal ganglia, globus pallidus and cerebellum. He has constipation, no sphincter control, sideropenic anaemia, fine motor skills difficulties. Both children have speech articulation difficulties. Child1 attends school according to an individual program. Child2 does not attend kindergarten, is not included in the early intervention program. 34year-old mother, a housewife, has an unrecognized NF1. During puberty, she had skin problems, spots and neurofibromas, itching. The family live in a house in the countryside, no car, no internet access. Public transport to the school, kindergarten and the nearest town is not organized. There are no speech therapists near the place of residence.

Conclusion Health surveillance of children with NF1 in primary pediatric care requires knowledge of clinical criteria and the various manifestations of the disease that may occur with age. NF1 is a multisystem disorder that requires multidisciplinary follow-up. Primary paediatrician takes on the role of coordinator. It is necessary to know the ability of the family to meet the intense rhythm of diagnostic and therapeutic interventions.

\section{CAN BENIGN AFEBRILE CONVULSIONS ASSOCIATED WITH MILD GASTROENTERITIS BE PREVENTED BY VACCINATION?}

Svjetlana Bela Klancir*, I Mrkić Kobal, G Krakar, F Sabol, Kovač Šižgorić, G Tešović, M Meštrović, S Delin, R Gjergja Juraški, V Đuranović, Z Sabol. Poliklinika za dječje bolesti dr. Sabol

10.1136/archdischild-2021-europaediatrics.492

Background Convulsions during mild viral gastroenteritis (CwG) represent a clinically recognized entity of benign 
afebrile seizures in children. Recent reports have shown that after the introduction of RV vaccine the incidence of RV-associated $\mathrm{CwG}$ decreased.

Aim To evaluate the demographic, electroclinical characteristics and outcome of CwG in children hospitalized in 6 Croatian centers in the period from 2008 to 2018.

This is a multicenter prospective study that included 40 patients hospitalized for CwG (male to female ratio 25:15). We collected medical records including data on gender, personal, family history of epileptic seizures, age on the time of first seizure, clinical type, duration and frequency of seizures, postictal/interictal electroencephalographic (EEG) features, antiepileptic therapy and the results of laboratory analysis (including stool specimens for virus antigens and bacterial stool specimen culture) and brain imaging. Patients follow up was performed in six-motnhs intervals during the first two years and later at intervals of 12-18 months (median time 44.5 months). Seizure types were classified using most current revised ILAE terminology.

Statistical analysis was performed using the SSPS Windows version 15.0 program.

The median age of children at the time of CwG onset was 15.5 months (range: 1 month to 6 years). Rotavirus was the most common cause of diarrhea (85\%).

Seizures most frequently occurred $(45 \%)$ on the third day of the gastrointestinal symptoms. Generalized seizures (90\%) were the most common clinical presentation. In a half of patients, the seizures came in clusters.

The attacks usually lasted for less than five minutes (85\%). In about half of the patient's seizures ceased spontaneously and usually lasted less than five minutes (85\%). Abnormal EEG was reported in 6 of 40 patients with CwG (15\%). Long-term antiepileptic therapy (phenobarbitone and valproic acid) was prescribed in $12 / 40$ patients (30\%) for 1-24 months. During the follow-up period of 37 children with $\mathrm{CwG}$, two children (5.4\%) had recurrence of CwG, two patients had febrile seizures and two children developed epilepsy.

Afebrile CwG represent a defined clinical condition with good prognosis and normal psychomotor development in most children. In a small number of cases, the risk of recurrence of CwG may exist, with the risk of the onset of febrile seizures and the development of epilepsy. Considering RV as the most common causative agent of diarrhea associated with convulsions, universal vaccination with RV vaccines should reduce the incidence of morbidity from RV disease and consequently reduce the occurrence of its complications - CwG.

\section{AVAILABILITY AND HEALTH CARE UTILIZATION IN THE PRE-SCHOOL CHILDREN'S HEALTH SERVICE IN THE CURATIVE-CARE DURING THE COVID-19 EPIDEMIC}

${ }^{1}$ Đurða Španović, 2Željka Draušnik*, ${ }^{2}$ Andrea Kostinčer-Pojić. ${ }^{1}$ Pediatric practice, Health centre Zagreb - East, Zagreb, Croatia; ${ }^{2}$ Division of Public Health, Croatian Institute of Public Health, Zagreb, Croatia

\subsection{6/archdischild-2021-europaediatrics.493}

Objectives To determine the impact of the COVID-19 epidemic on the availability and health care utilization in the pre-school children's health service in Croatia.

Methods We used data from pre-school children's health service, where about $90 \%$ of preschool children receive health care, obtained through Central Health Information System of the Republic of Croatia. Number of contacts with health care providers, examinations and counselling, as well as number of issued referrals and prescriptions during 2019 and 2020, for children up to six years of age, in curative-care, were analyzed.

Results During 2020, 232,583 children sought health care in pre-school children's health service, which is a decrease of $2.7 \%$ in regard to 2019 , when 239,148 children were registrated. The number of contacts with health care, which includes visits, examinations, telecommunications etc., also decreased, by $16.6 \%$ (2020: 1,977,417; 2019: 2,372,249). In curative-care examinations a decrease of $42.0 \%$ was recorded (2020: 704,584; 2019: 1,214,178), but an increase of $12.0 \%$ was recorded in curative- counselling (2020: 1,016,716; 2019: $907,894)$, with $80 \%$ increase in curative-counseling by e-mail and/or telephone.

The number of issued referrals and prescriptions also shows a decrease in 2020 compared to 2019. During 2020, 410,933 referrals were issued, and in 2019 530,626 referrals, which is a decrease of $22.6 \%$, however, the share of different types of referrals remained almost unchanged in both years, and the share of referrals to the hospital emergency departments did not increase either.

During 2019, 1,181,889 prescriptions were prescribed, with the highest share of beta-lactam penicillins - 13.3\%. During 2020, 923,002 prescriptions were prescribed, a decrease of $21.9 \%$, with the largest share of the subgroup of vitamins $11.4 \%$.

Conclusion By declaring the COVID-19 epidemic in Croatia, the Minister of Health, in order to protect the health of health-care workers and patients, recommended the maximum possible reduction of patients' visits to medical practices and performing only urgent examinations and procedures during the epidemic, while increasing the availability of telecommunication contancts with patients. This analysis shows that in 2020, the use of health care in the pre-school children's health service also decreased, but it was not significant. It is important to emphasize that although the number of examinations of sick children has decreased, the number of curative counselling has increased, especially those provided by phone and e-mail, which indicates a rapid response of pediatricians to the new situation and greater use of telecommunication channels in regular communication with parents which helped in maintaining the availability of healh care system.

The decrease in the number of prescriptions can be explained by the closure of preschools in the spring of 2020 and the subsequent lower frequency of contact among children, but requires more detailed morbidity analyzes and the anlyzes of possible SARS-CoV-2 impact on other pathogens characteristic for that age.

\section{A CHILD WITH DENSE DEPOSIT DISEASE AND DECREASED CLASSICAL PATHWAY ACTIVITY}

${ }^{1}$ Ivana Trutin*, 'Lea Oletić, ${ }^{2,3}$ Danko Milošević. ${ }^{1}$ Pediatric Department, Sestre milosrdnice University Hospital Center, Vinogradska cesta 29, 10000, Zagreb, Croatia; ${ }^{2}$ University of Zagreb, School of Medicine, Salata 3, Zagreb, Croatia; ${ }^{3}$ University Hospital Centre Zagreb, Kispaticeva 12, 10000, Zagreb, Croatia

\subsection{6/archdischild-2021-europaediatrics.494}

C3 glomerulopathy (C3G) is a rare kidney disease caused by abnormal control of complement activation and includes dense deposit disease (DDD) and C3 glomerulonephritis. DDD 